\author{
부직포 멀칭 방식에 따른 종가시나무 묘목의 \\ 생장과 제초에 미치는 영향 \\ 성창현 ${ }^{*}$ 윤준혁** 진언주 ${ }^{* * *} \cdot$ 배은지 ${ }^{* *}$ \\ *국립산림과학원 산림바이오소재연구소 석사연구원 · \\ "국립산림과학원 산림바이오소재연구소 연구사. "국립산림과학원 산림바이오소재연구소 박사연구원

\section{The Effect of Polypropylene Mulching Method on Growth of Quercus glauca Thunb. Seedling and Weed Treatments} \\ Sung, Chang-Hyun ${ }^{*} \cdot$ Yoon, Jun-Hyuck ${ }^{* *} \cdot$ Jin, Eon-Ju ${ }^{* * *} \cdot$ Bae, Eun-Ji* \\ *Post-Master Researcher, Forest Biomaterials Research Center, National Institute of Forest Science \\ "Research Scientist, Forest Biomaterials Research Center, National Institute of Forest Science \\ Post-Doctoral Researcher, Forest Biomaterials Research Center, National Institute of Forest Science
}

\begin{abstract}
Recently, cultivation and management technologies have been needed to adapt due to climate change, which is causing abnormal weather conditions. One technique is to increase the utilization of evergreen broad-leaved species with high ornamental value. A total of five treatments were installed $(1 \mathrm{~m} \times 22.5 \mathrm{~m})$, including $60 \mathrm{~g} / \mathrm{m}^{2}$ and $80 \mathrm{~g} / \mathrm{m}^{2}$ using two types mulching material with an overlapping and hole-drilling mulching method and these were compared to un-mulching treatment a total of planted $92 \mathrm{~m}^{2}$ attheWol-aTestSiteForestattheForestforBiomaterialsResearchCenterinJinju-si, Gyeongsangnam-dofor 10monthsusing3-years-oldQuercusglaucaThunb. In comparison with the control site, the $60 \mathrm{~g} / \mathrm{m}^{2}$ overlapping method was about 1.9 times higher than the root collar diameter, but there was no statistical significance between the treatments. Healthy seedlings were found to meet these conditions due to high biomass values and below and $\mathrm{T} / \mathrm{R}$ ratios of 3.0 or lower and H/D ratios of 7.0 or lower. Comparing the values of LWR, SWR, and RWR, which can be evaluated for seedling due to the mulching treatments, as compared to the control, the growth of the ground areas including leaves and stems was enhanced, but the growth of the underground areas containing roots tended to have high control values. Based on this, the SQI value, which can be evaluated for the comprehensive quality of seedlings, was found to be significantly different between the control site and the mulching treatment sites, confirming that the growth and growth improvement effects were achieved with mulching treatments. The chlorophyll content analysis showed that there was a significant difference from the control site, and it was judged that weed generation in the control acted as an environmental stress, causing a decrease in chlorophyll content. It was found that the overlapping $80 \mathrm{~g} / \mathrm{m}^{2}$ of polypropylene mulching material generated about 4 times fewer weeds than the control, and the manpower required for the mulching test field and weeding were equal at 3.3 people $/ 100 \mathrm{~m}^{2} / 1$ day. Mulching treatments have demonstrated a significant difference in the promotion of growth and quality of the seedlings and are judged as an alternative that can reduce the economic burden incurred by the purchase of the supplies and the manpower required to weed forestry plantations.
\end{abstract}

Corresponding author: Jun-Hyuck Yoon, Research Scientist, Forest Biomaterials Research Center, National Institute of Forest Science, Jinju 52817, Korea, Tel.: +82-55-760-5031, E-mail: jhyoon7988@korea.kr 


\section{Key Words: Quercus Glauca Thunb., Mulching Treatment, Growth, Quality, Weeding}

\section{국문초록}

최근 이상기후 등 기후변화에 적응하고 관상가치가 높은 상록활엽수의 활용을 높이기 위한 재배 및 관리 기술이 요구되고 있다. 종가시나무 (Quercus glauca Thunb.) 1-2묘를 공시수종으로 하여 10개월간 경남 진주시 금산면에 위치한 산림바이오소재연구소 월아 시험림에서 $1 \mathrm{~m} \times 22.5 \mathrm{~m}$ 크기의 묘상을 만들어 부직포 멀칭 소재 $60 \mathrm{~g} / \mathrm{m}^{2}, 80 \mathrm{~g} / \mathrm{m}^{2}$ 두 종류와 멀칭 방식 겹치기, 구멍딿기 두 방식 그리고 멀칭을 하지 않은 대조구 총 5 개 처리구로 각각 92 본씩 시험지를 조성 하였다. 부직포 멀칭 소재 $60 \mathrm{~g} / \mathrm{m}^{2}$ 겹치기 방식은 대조구와 비교 시 묘고는 약 1.9 배 근원경은 약 1.1 배 더 높은 값을 보였으며, 처리 간의 통계적 유의성은 없었다. 건전한 묘목은 $\mathrm{H} / \mathrm{D}$ ratio 7.0 이하, T/R ratio 3.0 이하, 부위별 물질 생산량 값이 높은 조건으로 분석 결과, 이를 만족하는 것으로 조사되었다. 멀칭 처리에 따른 묘목의 품질을 평가할 수 있는 LWR, SWR, RWR 값을 대조구와 비교해 보면, 잎과 줄기를 포함하는 지상부의 생장은 증진되었지만, 뿌리를 포함하는 지하부의 생장은 대조구 값이 높은 경향을 보였다. 이를 바탕으로 묘목의 종합적인 품질을 평가할 수 있는 SQI 값은 대조구와 멀칭 처리간의 유의적인 차이가 있는 것으로 나타나, 멀칭 처리에 따른 생육증진 효과가 있음을 확인하였다. 엽록소 함량 분석에서는 대조구와 유의적인 차이가 있는 것으로 나타났는데, 대조구의 잡초 발생이 환경스트레스로 작용하여 엽록소 함량의 저하를 야기한 것으로 판단된다. 부직포 멀칭 소재 $80 \mathrm{~g} / \mathrm{m}^{2}$ 겹치기 방식은 잡초 발생량이 대조구 대비 약 4 배 더 적게 발생하며, 식재지 조성인력과 제초작업에 소요되는 총 작업인력은 3.3 인 $/ 100 \mathrm{~m}^{2} / 1$ 일이 소요되는 것으로 조사되었다. 멀칭처리는 묘목의 생장과 품질 그리고 제초에 유의적인 차이가 있는 것으로 나타나 생육증진 효과가 있으며, 대규모 식재지를 포함한 일반수목 생산지에서의 제초작업에 투입되는 인력수급의 경제적인 부담을 줄일 수 있는 대안으로 판단된다.

주제어: 종가시나무, 멀칭 처리, 생장, 품질, 제초

\section{I. 서론}

종가시나무 (Quercus glauca Thunb.)는 상록활엽수로 사계 절 푸른 잎을 보이며 노동력이 작게 투입되어도 공간적, 시각 적 아름다운 자연환경을 제공해주는 관상가치가 높은 수종으 로 각광받고 있다 (Oh and $\mathrm{Kim}, 2006)$. 내한성이 약해 수도권 지역에서의 생육은 어렵지만, 낙엽활엽수보다 상대적으로 내음 성이 강하여 실내와 같은 반음지에서도 생육이 가능한 수종이 다(Lee and Kim, 2017). 또한, 내병성 및 내충성에도 강하여 도심지 조경수, 공원수, 정원수 등으로 활용가치가 높은 수종이 다(Choi et al., 2012).

종가시나무 (Quercus glauca Thunb.)는 분류학적으로 참나 무과에 속하며, 남부지방과 제주도의 표고 $600 \mathrm{~m}$ 이하에 자생 하고, 수고 15 20m로 가지에 털이 없다. 형태학적으로 잎은 장 타원형으로 길이는 7 $12 \mathrm{~cm}$, 너비는 $2.5 \sim 3.5 \mathrm{~cm}$ 로 표면에는 윤 기가 있고, 가장자리에는 톱니가 있다. 열매는 반구형으로 크기 는 6 9mm 이며, 5 6개의 원 무늬와 잔털이 있는 도토리집에 $1 / 3$ 정도 들어가 있다(National Institute of Biological Resources, https://species.nibr.go.kr).

국립기상과학원 (National Institute of Meteorological Sciences, NIMR)은 '신 기후변화 시나리오에 따른 미래기후 전망 및 기
후변화 영향(2011)' 세미나에서 2050년까지 우리나라는 평균 기온 $3.2^{\circ} \mathrm{C}$, 강수량 $16 \%$, 전 해상 해수면 $27 \mathrm{~cm}$ 상승할 것이라 고 전망했다. 따라서 변화하는 기후 환경에 적응하고 관상가치 가 높은 상록활엽수의 이용을 높이기 위한 재배 및 관리기술의 개발이 필요하다.

대단위 면적의 수목 식재지는 인력과 기계에 의한 제초작업 으로 사후관리비에 제초작업의 비중이 크게 작용하므로 (Park et al., 2004) 제초작업은 묘목을 재배하는 농가에서의 생산단 가를 높일 수 있는 중요한 요인으로 작용한다.

상록활엽수종의 조림 또는 산림복원을 위한 묘목은 세근발 달 및 뿌리의 활착 저조의 문제가 있어, 일반적인 조림수종들에 비해 활착·생존율이 낮은 것으로 조사되었다.

멀칭은 토양의 표면을 피복하여 잡초 발생 방지효과와 지온 조절효과가 있어 제초작업 비용을 절감할 수 있으며, 토양 수 분을 유지하여 작물의 생장을 증진시키는 효과가 있어 건전한 묘 목으로 생산하는데 이점이 될 것이다(Hong et al., 2011, Shin et al., 2012).

목적에 따라 다양한 피복 재료를 선택 가능하며, 폴리에틸렌 이나 염화비닐 필름과 같은 플라스틱 필름이 널리 이용되고 (Jensen, 1988; Unger, 1978) 있으며, 영농 폐비닐은 매년 전국 에서 5 6만톤이 수거되지 못하고 방치되면서 환경오염 등 사 
회적 문제가 발생되고 있다.

최근에는 물과 액상비료가 통과할 수 있는 polypropylene 소 재의 부직포를 개발하여 사용하고 있으며, 이를 이용한 적용 사례가 적고 노동력 부족 및 인건비 상승의 이유로 멀칭의 관 심이 증가하고 있는 추세다.

따라서 polypropylene 소재의 부직포를 이용하여 멀칭 처리 가 종가시나무 (Quercus glauca Thunb.) 묘목 재배 시 묘목의 생장과 제초에 미치는 영향을 살펴보고, 상록활엽수의 활용가 치를 높이고자 실험을 실시하였다.

\section{II. 재료 및 방법}

\section{1. 공시 수종 및 시험지 조성}

공시수종은 산림바이오소재연구소에서 양묘된 묘고 $11.7 \pm 3.0$,

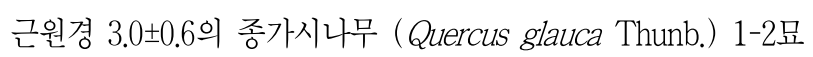
(3년생, 1년생 묘를 이식하여 2년 키운 묘)를 진주시 금산면에 위치한 월아 시험림에서 $1 \mathrm{~m} \times 22.5 \mathrm{~m}$ (가로×세로) 크기의 묘상 을 만들어 1처리구당 2열씩 총 92본을 식재하였으며, 시험기간 은 2014년 4월부터 10월까지 (10개월간) 수행하였다(Figure 1 참조).

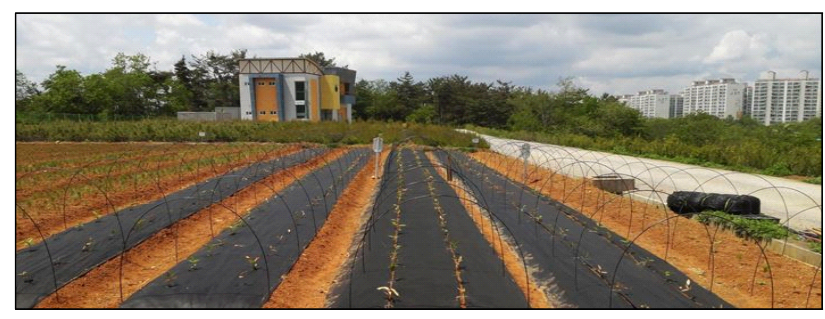

Figure 1. Weed yield by polypropylene mulching treatments(Left: $60 \mathrm{~g} / \mathrm{m}^{2}$ overlapping, $60 \mathrm{~g} / \mathrm{m}^{2}$ hole drilling, $80 \mathrm{~g} / \mathrm{m}^{2}$ overlapping, $80 \mathrm{~g} / \mathrm{m}^{2}$ hole drilling, Control)

\section{2. 멀칭 처리}

멀칭 처리는 단위중량 $60 \mathrm{~g} / \mathrm{m}^{2}, 80 \mathrm{~g} / \mathrm{m}^{2}$ 2가지 polypropylene (PP) 소재의 부직포를 사용하였으며, 묘목 식재 위치에 구멍 을 딿어 식재하는 구멍딿기 방식과 묘목 식재 후 지상으로 노 출되게 부직포를 겹쳐서 설치하는 겹치기 방식으로 농가에서 가장 널리 이용하고 있는 2가지 방식으로 설치하였다. 멀칭을 하지 않은 대조구를 포함한 5개 처리구로 처리하였다(Figure 2 참조).

\section{3. 온·습도}

대조구와 부직포 멀칭 재료 $60 \mathrm{~g} / \mathrm{m}^{2}, 80 \mathrm{~g} / \mathrm{m}^{2}$ 처리구의 지표

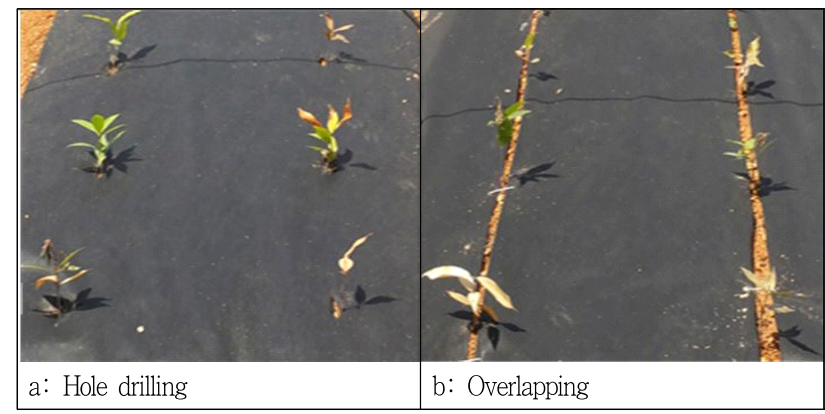

Figure 2. The polypropylene mulching method on weed treatments

면 $5 \mathrm{~cm}$ 깊이에 각각 토양 온·습도 측정기 (H21-USB, Onset Computer Corp. Boume, MA, USA)를 설치하여 처리구별 토 양 내 온·습도를 측정하였다.

\section{4. 생장 특성 및 품질지수 분석}

멀칭 처리 별 종가시나무 (Quercus glauca Thunb.) 묘목의 생장에 따른 특성을 조사하기 위해 정식 직후 2014년 4월과 시 험이 종료되는 2014년 10월에 전자식 캘리퍼스 (Absloute Digimatic Caliper-500, Mitutoyo, Kanagawa, Japan)를 이용하여 92 본씩 전체 5 개 처리구의 묘고 $(\mathrm{cm})$ 와 근원경 $(\mathrm{mm})$ 을 각각 측 정하였고, 이를 바탕으로 묘고와 근원경에 대한 상대생장량을 계산하여 H/D ratio (Height/Root collar diameter ratio)를 산 출하였다(Figure 3 참조). 데이터는 측정된 평균치 범위 내에 서 3 반복하여 사용하였다.

부위별 물질 생산량은 생장 특성 조사가 끝난 직후 2014년 10 월에 묘고와 근원경의 평균값을 보이는 묘목 3 본을 굴취하여 잎, 줄기, 뿌리의 생중량을 측정하고 $65^{\circ} \mathrm{C}$ 에서 48 시간 건조시켜 각각의 건중량을 측정하였다. 이를 활용하여 T/R ratio (Top dry weight/Root dry weight ratio)를 산출하였다. 부위별 물질 생 산량의 값이 높고 (Bayala et al., 2009; Davis and Jacobs, 2005; Dickson et al., 1960), T/R ratio 값이 3.0 이하 (Haase, 2007a; 2007b)일 때가 건전한 묘목의 조건이다.

품질지수 분석은 부위별 물질 생산량 값을 바탕으로 엽 건중비 (leaf dry weight ratio, LWR), 줄기 건중비 (shoot dry weight ratio, SWR), 뿌리 건중비 (root dry weight ratio, RWR)를 계

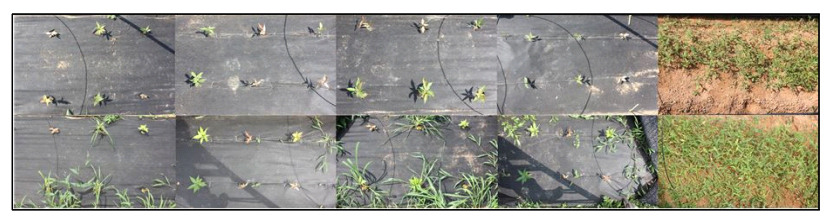

Figure 3. Growth condition of Quercus glauca Thunb. seeding by polypropylene mulching treatments(Left: $60 \mathrm{~g} / \mathrm{m}^{2}$ overlapping, $60 \mathrm{~g} / \mathrm{m}^{2}$ hole drilling, $80 \mathrm{~g} / \mathrm{m}^{2}$ overlapping, $80 \mathrm{~g} / \mathrm{m}^{2}$ hole drilling, Control, Up: Aprill, Down: June) 
산하였고, 종합적으로 양묘된 묘목의 품질을 최종 판단할 수 있는 묘목품질지수 (seedling quality index)를 산출하였다 (Bayala et al., 2009; Deans et al., 1989; Dickson et al., 1960; Šestak et al., 1971).

${ }^{\circ} \mathrm{H} / \mathrm{D}$ ratio $(\mathrm{cm} / \mathrm{mm})=$ Height $(\mathrm{cm}) /$ Root collar diameter $(\mathrm{mm})$

${ }^{\circ} \mathrm{T} / \mathrm{R}$ ratio $(\mathrm{g} / \mathrm{g})=\mathrm{Top}$ (leaf+shoot, g) dry weight/Root dry weight $(\mathrm{g})$

${ }^{\circ} \mathrm{LWR}(\mathrm{g} / \mathrm{g})=$ Leaf dry weight $(\mathrm{g}) /$ Total dry weight $(\mathrm{g})$

${ }^{\circ} \operatorname{SWR}(\mathrm{g} / \mathrm{g})=$ Shoot dry weight $(\mathrm{g}) /$ Total dry weight $(\mathrm{g})$

${ }^{\circ}$ RWR $(\mathrm{g} / \mathrm{g})=$ Root dry weight $(\mathrm{g}) /$ Total dry weight $(\mathrm{g})$

${ }^{\circ} \mathrm{SQI}(\mathrm{g} / \mathrm{g})=$ Total dry weight $(\mathrm{g}) /(\mathrm{H} / \mathrm{D}$ ratio+T/R $\operatorname{ratio}(g))$

\section{5. 엽록소 함량 분석}

멀칭 처리에 따른 종가시나무 (Quercus glauca Thunb.) 묘 목의 광합성 반응 검증을 위해 엽록소 함량을 측정하였다. 시 험이 종료되는 2014년 10 월에 멀칭 처리별 건전한 잎을 3 반복 으로 채취하여 용매 DMSO (dimethylsulfoxide)에 담궈 $65^{\circ} \mathrm{C}$ 항온수조에서 6시간 진탕하여 엽록소를 추출하였다(Hiscox \& Israelstam, 1979).

UV/VISIBLE spectrophotometer (Biochrom Libra S22, Shimadzu Corp., Kyoto, Japan)을 이용하여 엽록소 추출액은 $663 \mathrm{~nm}$ 와 $645 \mathrm{~nm}$ 파장에서 흡광도를 측정하였고, 이를 활용하여 엽록소 함량을 산출하였다(Arnon, 1949; Mackinney, 1941).

${ }^{\circ}$ Chlorophyll a(mg/g Fresh weight $)=12.7 \times$ A663 $-2.69 \times$ A645

${ }^{\circ}$ Chlorophyll b(mg/g Fresh weight $)=22.9 \times$ A645 $-4.68 \times$ A663

- Total chlorophyll (mg/g fresh weight)

$=20.20 \times \mathrm{A} 645+8.02 \times \mathrm{A} 663$

\section{6. 작업공정 및 잡초 발생량 조사}

멀칭 처리 별 식재지 조성인력과 제초작업 소요인력은 4 명이 한 처리구당 줄 맞춤, 식재, 부직포 설치 시 소요되는 시간과

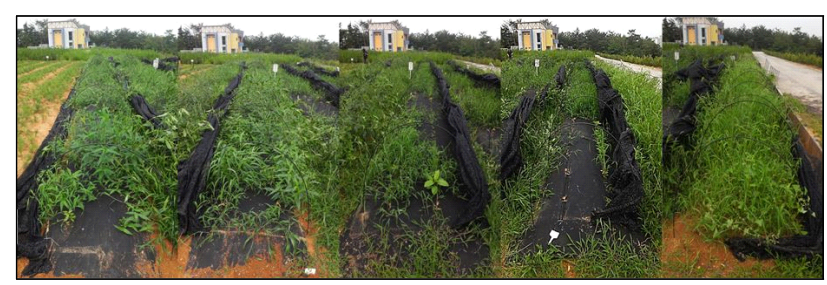

Figure 4. Weed yield by polypropylene mulching treatments(Left: $60 \mathrm{~g} / \mathrm{m}^{2}$ overlapping, $60 \mathrm{~g} / \mathrm{m}^{2}$ hole drilling, $80 \mathrm{~g} / \mathrm{m}^{2}$ overlapping, $80 \mathrm{~g} / \mathrm{m}^{2}$ hole drilling, Control)
한 처리구당 제초작업에 소요되는 시간을 각각 측정하여 1 인/ $100 \mathrm{~m}^{2} / 1$ 일로 환산 적용하여 계산하였다(Kim and Park, 2010).

잡초 발생량 조사는 멀칭 처리별 발생한 잡초 (Figure 4 참 조)를 채취하여 깨끗이 세척한 뒤 생중량을 측정하고, $65^{\circ} \mathrm{C}$ 에 서 48시간 건조 후 건중량을 측정하였으며 (Roh et al., 2004; Lee et al., 2010), 표기는 건중량 $\left(\mathrm{g} / 100 \mathrm{~m}^{2}\right)$ 으로 하였다.

\section{7. 통계분석}

멀칭 처리가 종가시나무 (Quercus glauca Thunb.) 묘목의 품질과 작업공정에 미치는 영향을 파악하기 위해 IBM SPSS Statistics (Version 21)을 이용하여 던컨다중검정 (Ducan's multiple range test)을 통해 평균값 간의 유의성 검증을 분석 하였다.

\section{III. 결과 및 고찰}

\section{1. 처리구별 온·습도}

멀칭시험기간 동안 처리구별 토양의 온·습도를 측정하여 하 루 중 상대습도가 가장 낮은 2시경에 월별로 토양수분 유지 기 능이 있는지를 살펴보았다(Table 1 참조). 8월 10월의 습도를 보면, 대조구의 평균은 $0.17 \pm 0.1 \%$ 로 매우 건조한 반면, 부직포 멀칭 소재 $60 \mathrm{~g} / \mathrm{m}^{2}$ 과 $80 \mathrm{~g} / \mathrm{m}^{2}$ 처리구의 평균은 각각 $24.4 \pm 1.8 \%$, $22.7 \pm 1.6 \%$ 로 습도가 유지되며, 대조구의 값과 뚜렷한 차이를 보였다. 멀칭은 토양수분을 유지하여 작물의 생장 증진에 관여 한다고 하였다(Lee et al., 2010). 본 시험에서도 멀칭 처리를 하면 습도 유지기능을 보여 여름 및 겨울의 건조피해로부터 감

Table 1. Monthly temperature and humidity pattern in soil by polypropylene mulching treatments

\begin{tabular}{|c|c|c|c|c|c|}
\hline \multicolumn{2}{|c|}{ Treatment } & \multirow{2}{*}{$\frac{\text { Apr. }^{\mathrm{c}}}{15.1 \pm 2.8}$} & \multirow{2}{*}{\multicolumn{2}{|c|}{$\frac{\text { May }}{17.2 \pm 2.8}$}} & Jun. \\
\hline \multirow{2}{*}{$60 \mathrm{~g} / \mathrm{m}^{2}$} & $\mathrm{Temp}^{\mathrm{a}}\left({ }^{\circ} \mathrm{C}\right)$ & & & & $21.1 \pm 1.2$ \\
\hline & $\operatorname{Hum}^{b}(\%)$ & $13.5 \pm 3.8$ & \multicolumn{2}{|c|}{$15.3 \pm 1.0$} & $14.6 \pm 1.4$ \\
\hline \multirow{2}{*}{$80 \mathrm{~g} / \mathrm{m}^{2}$} & Temp $\left({ }^{\circ} \mathrm{C}\right)$ & $15.4 \pm 2.4$ & \multicolumn{2}{|c|}{$17.8 \pm 2.3$} & $21.6 \pm 1.3$ \\
\hline & $\operatorname{Hum}(\%)$ & $12.1 \pm 3.5$ & \multicolumn{2}{|c|}{$14.1 \pm 0.8$} & $14.4 \pm 1.0$ \\
\hline \multirow{2}{*}{ Control } & Temp $\left({ }^{\circ} \mathrm{C}\right)$ & $15.5 \pm 4.1$ & \multicolumn{2}{|c|}{$17.9 \pm 3.5$} & $21.7 \pm 2.1$ \\
\hline & $\operatorname{Hum}(\%)$ & $19.0 \pm 3.4$ & \multicolumn{2}{|c|}{$18.7 \pm 1.8$} & $17.9 \pm 1.8$ \\
\hline \multicolumn{2}{|c|}{ Treatment } & Jul. $^{d}$ & Aug. ${ }^{e}$ & Sep. ${ }^{f}$ & Oct. ${ }^{g}$ \\
\hline \multirow{2}{*}{$60 \mathrm{~g} / \mathrm{m}^{2}$} & Temp $\left({ }^{\circ} \mathrm{C}\right)$ & $24.3 \pm 2.2$ & $24.5 \pm 1.5$ & $25.2 \pm 1.8$ & $22.4 \pm 1.0$ \\
\hline & $\operatorname{Hum}(\%)$ & $21.5 \pm 4.9$ & $26.1 \pm 2.5$ & $24.6 \pm 8.8$ & $22.5 \pm 5.3$ \\
\hline \multirow{2}{*}{$80 \mathrm{~g} / \mathrm{m}^{2}$} & Temp $\left({ }^{\circ} \mathrm{C}\right)$ & $24.7 \pm 2.0$ & $24.7 \pm 1.4$ & $22.0 \pm 1.7$ & $19.8 \pm 2.4$ \\
\hline & $\operatorname{Hum}(\%)$ & $18.2 \pm 3.8$ & $24.3 \pm 1.6$ & $22.8 \pm 4.0$ & $21.0 \pm 1.0$ \\
\hline \multirow{2}{*}{ Control } & $\operatorname{Temp}\left({ }^{\circ} \mathrm{C}\right)$ & $24.3 \pm 4.3$ & $24.4 \pm 1.5$ & $25.2 \pm 1.9$ & $22.5 \pm 1.0$ \\
\hline & $\operatorname{Hum}(\%)$ & $23.8 \pm 4.7$ & $0.2 \pm 0.1$ & $0.2 \pm 0.1$ & $0.1 \pm 0.1$ \\
\hline
\end{tabular}

a Temperature, ${ }^{\mathrm{b}}$ Humidity, ${ }^{\mathrm{c}}$ April, ${ }^{\mathrm{d}}$ July, ${ }^{\mathrm{e}}$ August, ${ }^{\mathrm{f}}$ September, ${ }^{\mathrm{g}}$ October. 
소할 수 있으며, 묘목의 생장 증진에도 영향을 미치는 것으로 판단된다.

\section{2. 형태적 생장 특성}

묘목의 품질을 판단할 수 있는 외형적 지표인 (Blair and Cech, 1974; Curtis, 1955) 근원경은 뿌리 생장의 잠재적 지표로 활용 되며 (Mullin and Christl, 1982), 뿌리의 생장잠재력이 우수하 면 수분이용능력이 높기 때문에 식재 후 활착율이 높다 (Carlson, 1986). 그리고 물질생산 배분 특성에 따른 $\mathrm{H} / \mathrm{D}$ 율과 $\mathrm{T} / \mathrm{R}$ 율로 묘목의 건전도를 평가할 수 있다(Hermann, 1964).

멀칭 처리에 따른 종가시나무 (Quercus glauca Thunb.) 묘 목의 묘고와 근원경의 상대생장량은 부직포 멀칭 소재 $60 \mathrm{~g} / \mathrm{m}^{2}$ 겹치기 방식에서 각각 $0.66 \pm 0.36 \mathrm{~cm}, 0.16 \pm 0.50 \mathrm{~mm}$ 로 유의적으 로 가장 높게 나타났다(Table 2 참조).

묘목의 건전도를 나타내는 $\mathrm{H} / \mathrm{D}$ ratio 값에서도 $4.61 \pm 0.72$ 로 유의적으로 가장 높은 값을 보였다. 묘고와 근원경 $\mathrm{H} / \mathrm{D}$ ratio 는 지하부 생장 대비 지상부 생장 비율을 뜻하며, 수종별 노지 묘의 적정 $\mathrm{H} / \mathrm{D}$ ratio에 대해 정리한 선행연구 (Johnson et al., 1996)에 의하면 활엽수 노지묘의 경우, 7.0 이하의 가장 높은 값일 때 건전한 묘목의 기준이라고 한 결과 (Haase, 2007a; 2007b)와 유사한 경향을 나타내었다.

이는 토양 내 습도 유기지능이 없는 대조구보다 습도 유지기능 이 있는 멀칭 처리가 형태적 생장 증진에 관여한 것으로 판단된다.

Table 2. Effect of polypropylene mulching treatments on height and root collar diameter growth, and H/D ratio of Quercus glauca Thunb. seedling

\begin{tabular}{|c|c|c|c|c|}
\hline \multirow{2}{*}{ Treatment } & \multicolumn{4}{|c|}{ Height } \\
\hline & \multicolumn{2}{|c|}{ Growth $(\mathrm{cm})$} & & $\mathrm{RGR}^{2}(\mathrm{~cm} /$ day $)$ \\
\hline $60 \mathrm{~g} / \mathrm{m}^{2}$ overlapping & \multicolumn{2}{|c|}{$25.17 \pm 9.53^{\mathrm{a}}$} & & $0.66 \pm 0.36^{\mathrm{a}}$ \\
\hline $60 \mathrm{~g} / \mathrm{m}^{2}$ hole drilling & \multicolumn{2}{|c|}{$22.16 \pm 9.57^{\mathrm{a}}$} & & $0.57 \pm 0.36^{b}$ \\
\hline $80 \mathrm{~g} / \mathrm{m}^{2}$ overlapping & \multicolumn{2}{|c|}{$21.38 \pm 6.99^{a}$} & & $0.53 \pm 0.24^{b}$ \\
\hline $80 \mathrm{~g} / \mathrm{m}^{2}$ hole drilling & \multicolumn{2}{|c|}{$20.60 \pm 10.43^{\mathrm{a}}$} & & $0.51 \pm 0.38^{b}$ \\
\hline Control & \multicolumn{2}{|c|}{$14.53 \pm 7.55^{b}$} & & $0.25 \pm 0.28^{c}$ \\
\hline \multirow{2}{*}{ Treatment } & \multicolumn{3}{|c|}{ Root collar diameter } & \multirow{2}{*}{$\mathrm{H} / \mathrm{D}^{\mathrm{y}}$ ratio $(\mathrm{cm} / \mathrm{mm})$} \\
\hline & Growth $(\mathrm{cm})$ & \multicolumn{2}{|c|}{$\mathrm{RGR}(\mathrm{cm} /$ day $)$} & \\
\hline $60 \mathrm{~g} / \mathrm{m}^{2}$ overlapping & $6.03 \pm 1.55^{\mathrm{a}}$ & \multicolumn{2}{|c|}{$0.16 \pm .050^{a}$} & $4.61 \pm 0.72^{\mathrm{a}}$ \\
\hline $60 \mathrm{~g} / \mathrm{m}^{2}$ hole drilling & $5.03 \pm 1.42^{b}$ & \multicolumn{2}{|c|}{$0.11 \pm 0.05^{b}$} & $3.66 \pm 1.80^{\mathrm{ab}}$ \\
\hline $80 \mathrm{~g} / \mathrm{m}^{2}$ overlapping & $5.09 \pm 1.42^{b}$ & \multicolumn{2}{|c|}{$0.11 \pm 0.04^{\mathrm{b}}$} & $3.49 \pm 0.27^{\mathrm{bc}}$ \\
\hline $80 \mathrm{~g} / \mathrm{m}^{2}$ hole drilling & $5.02 \pm 1.82^{b}$ & \multicolumn{2}{|c|}{$0.11 \pm 0.06^{b}$} & $3.84 \pm 0.63^{\mathrm{ab}}$ \\
\hline Control & $3.89 \pm 1.18^{c}$ & \multicolumn{2}{|c|}{$0.05 \pm 0.04^{c}$} & $2.74 \pm 0.63^{c}$ \\
\hline
\end{tabular}

${ }^{2}$ Relative rowth rate.

${ }^{\mathrm{y}} \mathrm{Height} / \mathrm{root}$ collar diameter.

" Data are the Mean \pm SE from the three replicates. Difference letters indicate treatments are significant difference at $p<0.05$ by Ducan's multiple range test.

\section{3. 부위별 물질 생산량}

외형적 지표 (형태학적 특성) 인자로 품질을 평가하기에는 부족한 부분이 있어 건중량 등의 양적 생장 및 지상부와 지하 부의 배분 비율 ( $\mathrm{T} / \mathrm{R}$ ratio)인 질적 생장을 동시에 고려하여 묘목품질지수로 평가할 수 있다(Dickson et al., 1960; Iyer and Wilde, 1982). 부위별 물질 생산량은 묘목의 근원경과 밀접한 연관성이 있으며 이식 후 생존과 생장에도 큰 영향을 미친다고 하였다(Swizer and Nelson, 1963; Ritchie, 1984).

멀칭 처리에 따른 부위별 물질 총 생산량과 $\mathrm{T} / \mathrm{R}$ ratio는 부직 포 멀칭 소재 $60 \mathrm{~g} / \mathrm{m}^{2}$ 겹치기 방식에서 각각 $6.55 \pm 1.42,2.12 \pm 0.63$ 으로 대조구보다 유의적으로 가장 높게 나타났다(Table 3 참조).

잎, 줄기, 뿌리 각각의 물질 생산량도 가장 높은 것으로 나타 나 선행연구 (Bayala et al., 2009; Davis and Jacobs, 2005; Dickson et al., 1960)와 동일한 결과를 나타내었고, 멀칭 처리 가 대조구보다 유의적인 차이가 있음을 확인하였다.

멀칭 처리는 종가시나무 (Quercus glauca Thunb.) 묘목의 생장을 증진시켜 (Park et al., 2004) 대조구보다 물질 생산량 이 높은 것으로 판단된다.

\section{4. 묘목품질지수}

묘목의 품질을 평가할 수 있는 인자에는 묘목 전체의 건물 생산량 중 잎에 대한 분배율을 뜻하는 LWR, 줄기에 대한 분배 율을 뜻하는 SWR, 뿌리에 대한 분배율을 뜻하는 RWR 그리

Table 3. Effect of polypropylene mulching treatments on growth characteristics of Quercus glauca Thunb. seedling

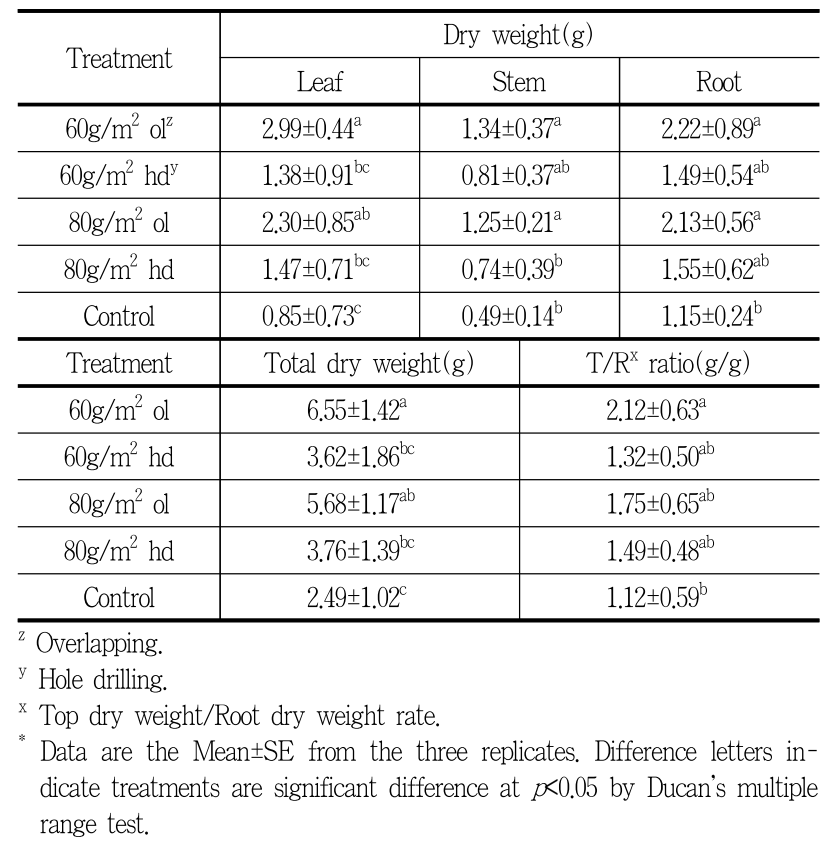


고 이를 바탕으로 종합적인 묘목의 품질을 평가하는 지표인 SQI가 있다(Lim et al,, 2009).

$\mathrm{LWR}$ 값은 대조구와 멀칭 처리 간의 유의적인 차이를 보였 고, SWR 값은 모든 처리에서 유의적인 차이가 없었다. RWR 값은 대조구 값이 유의적으로 가장 높게 나타나 멀칭 처리가 낮은 것으로 나타났다(Table 4 참조). RWR 값은 시비처리 후 무처리보다 낮아지는 경향(Sung et al., 2011)을 보이며, 질소 시비에 따라 그 값은 감소한다고 보고하였다(Reynolds and Antonio, 1996). 시비처리 효과와 멀칭 처리에 따른 생육증진 효과를 같은 효과로 본다고 할 경우 멀칭 처리구의 값이 낮게 나타나 비슷한 경향을 보였다.

$\mathrm{SQI}$ 값은 대조구보다 멀칭 처리가 유의적인 차이가 있는 것 으로 나타나, 멀칭 처리에 따른 묘목의 생장증진 효과가 있었 고, SQI 값이 가장 높은 멀칭 처리구는 부직포 멀칭 소재 $60 \mathrm{~g} /$ $\mathrm{m}^{2}$ 과 $80 \mathrm{~g} / \mathrm{m}^{2}$ 겹치기 방식으로 조사되었다. SQI는 묘목이 일정 한 기간 동안 정상적인 생장을 하였을 때 그 값이 클수록 건전한 묘목이라고 평가한다(Thompson, 1985; Mattsson, 1996; Bayala et al., 2009; Yoon et al., 2014; Kim et al., 2015). 멀칭 처리는 건전한 묘목으로 생산하는데 도움을 주는 것으로 판단된다.

\section{5. 엽록소 함량}

광합성 능력이 우수한 묘목은 식재 후에도 우수한 생장과 높 은 활착률을 나타낸다(Leiva and Fernandez-Ales, 1998). 광합 성 활동이 활발하면 근계로의 발달로 이어지며, 지상부로의 양 분과 수분의 흡수력과 이동력이 향상되어 식재 후 뿌리의 활착 을 돕는 것이다(Burdett, 1990). 멀칭 처리한 묘목과 대조구의 묘목을 대상으로 엽록소 함량을 측정하였다(Figure 5 참조).

식물이 광합성을 하기 위한 필수 색소인 엽록소 함량을 분석 해 보면 광합성 효율을 간접적으로 추정하여 환경스트레스에

Table 4. Effect of polypropylene mulching treatments on LWR, SWR, RWR, SQl of Quercus glauca Thunb. seedling

\begin{tabular}{c|l|l|l|l}
\hline Treatment & $\mathrm{LWR}^{\mathrm{z}}(\mathrm{g} / \mathrm{g})$ & $\mathrm{SWR}^{\mathrm{y}}(\mathrm{g} / \mathrm{g})$ & RWR $^{\mathrm{x}}(\mathrm{g} / \mathrm{g})$ & $\mathrm{SQI}^{\mathrm{w}}(\mathrm{g} / \mathrm{g})$ \\
\hline $\begin{array}{c}60 \mathrm{~g} / \mathrm{m}^{2} \\
\text { overlapping }\end{array}$ & $0.466 \pm 0.081^{\mathrm{a}}$ & $0.204 \pm 0.025^{\mathrm{a}}$ & $0.331 \pm 0.065^{\mathrm{b}}$ & $1.02 \pm 0.36^{\mathrm{a}}$ \\
\hline $\begin{array}{c}60 \mathrm{~g} / \mathrm{m}^{2} \\
\text { hole drilling }\end{array}$ & $0.305 \pm 0.150^{\mathrm{ab}}$ & $0.190 \pm 0.102^{\mathrm{a}}$ & $0.339 \pm 0.161^{\mathrm{ab}}$ & $0.65 \pm 0.32^{\mathrm{ab}}$ \\
\hline $\begin{array}{c}80 \mathrm{~g} / \mathrm{m}^{2} \\
\text { overlapping }\end{array}$ & $0.397 \pm 0.102^{\mathrm{ab}}$ & $0.224 \pm 0.043^{\mathrm{a}}$ & $0.379 \pm 0.086^{\mathrm{ab}}$ & $1.09 \pm 0.21^{\mathrm{a}}$ \\
\hline $\begin{array}{c}80 \mathrm{~g} / \mathrm{m}^{2} \\
\text { hole drilling }\end{array}$ & $0.396 \pm 0.104^{\mathrm{ab}}$ & $0.192 \pm 0.040^{\mathrm{a}}$ & $0.412 \pm 0.073^{\mathrm{ab}}$ & $0.74 \pm 0.35^{\mathrm{ab}}$ \\
\hline \begin{tabular}{c} 
Control \\
\hline
\end{tabular} & $0.295 \pm 0.148^{\mathrm{b}}$ & $0.206 \pm 0.033^{\mathrm{a}}$ & $0.499 \pm 0.128^{\mathrm{a}}$ & $0.64 \pm 0.21^{\mathrm{b}}$ \\
\hline
\end{tabular}

${ }^{z}$ Leaf dry weight ratio, ${ }^{y}$ Shoot dry weight ratio,

${ }^{x}$ Root dry weight ratio, ${ }^{\text {w }}$ Seedling quality index.

* Data are the Mean \pm SE from the three replicates. Difference letters indicate treatments are significant difference at $p<0.05$ by Ducan's multiple range test.

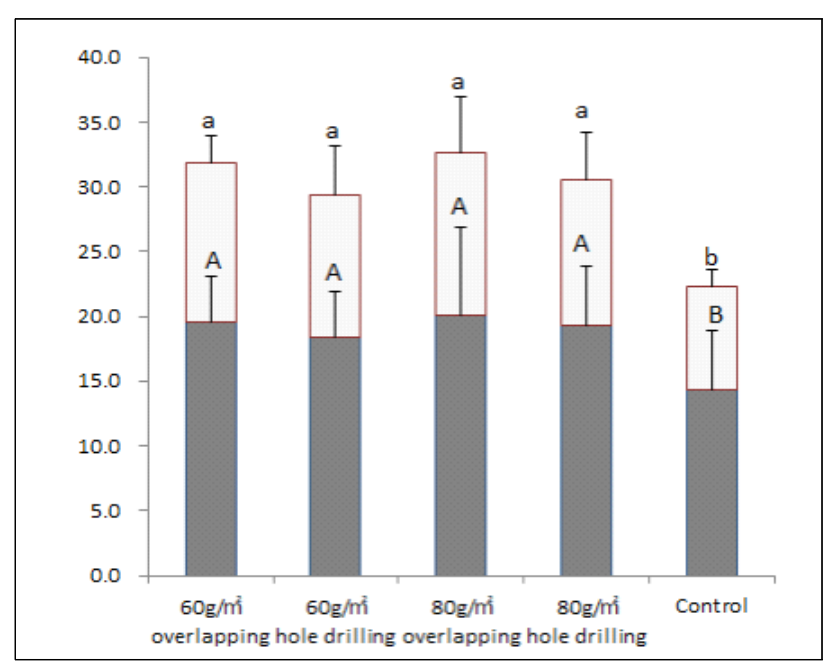

Figure 5. Effect of polypropylene mulching treatments on chlorophyll contents in Quercus glauca Thunb. seeding. Difference in the superscript alphabets $(a \sim c, A \sim B)$ of the indicates significant difference $(p<0.05)$.

Legend: $\square$ chlorophyll a $\square$ chlorophyll b

피해를 받고 있는지 알 수 있다(Baczek and Koscielniak, 2003). 엽록소 성분비와 전체 함량은 밀접한 관계가 있으며, 생태학적 으로 중요한 요인이다.

멀칭 처리에 따른 엽록소 함량 측정 결과, 대조구보다 멀칭 처리구가 높았지만 멀칭 처리 간 엽록소 $\mathrm{a}$ 와 $\mathrm{b}$ 값 모두 유의적 인 차이가 없는 것으로 나타났다. 멀칭 처리를 하지 않은 대조 구는 잡초 발생으로 인해 묘목의 생육 저하와 같은 환경 스트 레스가 가해져 잎의 엽록소 함량이 감소하게 되고, 높은 광을 이용하기 위해 잎에서는 많은 양의 엽록소를 생산하기 위해 질 소가 분배된다. 이는 곧 묘목의 품질을 불량하게 하는 결과로 초래될 수 있다(Naidu and Delucia, 1998).

대조구와 멀칭 처리구와의 유의적인 차이는 있지만, 멀칭 처 리 간 유의적인 차이는 없는 것으로 나타났다. 대조구에 다량 의 잡초 발생으로 인한 환경 스트레스가 엽록소 함량 저하로 이어져 종가시나무 (Quercus glauca Thunb.) 묘목의 품질 저 하를 야기한 것으로 판단된다.

\section{6. 작업공정 및 잡초 발생량}

제초작업의 효율화로 재배 공정의 절감효과 (Park et al, 2004; Roh et al., 2004; Sagong et al., 2011; Kang et al., 2013; Jin et al., 2015; Kang et al., 2017)와 묘목의 고품질화를 (Lim et al., 2009; Lee et al., 2010) 위한 부직포 멀칭 처리와 멀칭을 하지 않은 대조구와의 시험지 조성인력 및 제초작업 소요인력 을 1 인 $/ 100 \mathrm{~m}^{2} / 1$ 일로 산출하여 비교하였다(Table 5 참조).

대조구의 시험지 조성인력이 가장 적게 소요된 것으로 조사 되었는데, 이는 부직포 멀칭 처리를 하지 않고 묘목 식재만 진 
Table 5. Effect of polypropylene mulching treatments on weed yield, manpower required of mulching test field and weeding

\begin{tabular}{c|c|c|c}
\hline Treatment & $\begin{array}{c}\text { MRM } \\
\text { (person } / 100 \mathrm{~m}^{2} \\
/ \text { day) }\end{array}$ & $\begin{array}{c}\text { MRW }^{\mathrm{y}} \\
\text { (person } / 100 \mathrm{~m}^{2} \\
/ \text { day) }\end{array}$ & $\begin{array}{c}\text { Weed yield } \\
(\text { dry weight, g/ } \\
\left.100 \mathrm{~m}^{2}\right)\end{array}$ \\
\hline $60 \mathrm{~g} / \mathrm{m}^{2}$ overlapping & 2.1 & 2.2 & $10.0 \pm 5.0^{\mathrm{c}}$ \\
\hline $60 \mathrm{~g} / \mathrm{m}^{2}$ hole drilling & 1.3 & 2.2 & $18.3 \pm 7.6^{\mathrm{bc}}$ \\
\hline $80 \mathrm{~g} / \mathrm{m}^{2}$ overlapping & 1.8 & 1.5 & $11.7 \pm 2.9^{\mathrm{c}}$ \\
\hline $80 \mathrm{~g} / \mathrm{m}^{2}$ hole drilling & 1.4 & 1.5 & $23.7 \pm 1.2^{\mathrm{b}}$ \\
\hline Control & 0.8 & 4.0 & $40.0 \pm 8.7^{\mathrm{a}}$ \\
\hline
\end{tabular}

${ }^{2}$ Manpower required of mulching

${ }^{y}$ Manpower required of weeding.

* Data are the Mean \pm SE from the three replicates. Difference letters indicate treatments are significant difference at $p<0.05$ by Ducan's multiple range test.

행한 결과로 해석할 수 있다.

멀칭 처리에 따른 시험지 조성인력은 멀칭 처리 간 비교 시 부직포 멀칭 소재 $60 \mathrm{~g} / \mathrm{m}^{2}$ 구멍뚫기 방식으로 조성하면 대조구 보다 약 1.6 배 더 소요되며, 가장 적게 소요되는 것으로 나타났 다. 멀칭 처리에 따른 잡초 발생량은 부직포 멀칭 소재 $60 \mathrm{~g} / \mathrm{m}^{2}$ 과 $80 \mathrm{~g} / \mathrm{m}^{2}$ 겹치기 방식이 가장 적게 발생하여 대조구와 유의 적인 차이가 있는 것으로 나타났으며, 처리간의 유의성은 없는 것으로 나타났다.

이를 바탕으로 제초작업에 소요되는 인력을 조사한 결과, 잡 초 발생량이 가장 많은 대조구는 4.0 인 $/ 100 \mathrm{~m}^{2} / 1$ 일이 소요되었고, 잡초 발생량이 가장 적은 처리구는 부직포 멀칭 소재 $80 \mathrm{~g} / \mathrm{m}^{2}$ 겹 치기 방식으로 1.5 인 $/ 100 \mathrm{~m}^{2} / 1$ 일이 소요되는 것으로 나타났다.

따라서 부직포 멀칭 소재 $80 \mathrm{~g} / \mathrm{m}^{2}$ 겹치기 방식은 종가시나무 (Quercus glauca Thunb.) 묘목 재배 시 잡초 발생량이 유의적으로 가장 적게 발생하고, 식재지 조성과 제초작업에 소요되는 총 작업 인력은 3.3 인 $/ 100 \mathrm{~m}^{2} / 1$ 일로 가장 효율적인 방식으로 조사되었다.

멀칭이 잡초의 발생억제에 관여(Park et al., 2004)하며, 작업 공정에 있어 식재지 조성비용과 제초작업 비용을 절감하는데 도움이 될 것으로 기대된다.

\section{IV. 결론}

이상기후에 대비하여 관상가치가 높은 상록활엽수의 활용을 높이기 위한 종가시나무 (Quercus glauca Thunb.) 1-2묘를 공시 수종으로 하여 부직포 멀칭 소재 두 종류와 멀칭 방식 두 종류 그리고 대조구를 포함한 5 개 처리구로 시험지를 조성하였다.

시험기간 동안 토양 내 온 - 습도를 측정하였고, 형태적 생장 특성 (묘고, 근원경, 상대생장량, H/D ratio), 부위별 물질 생산 량 (부위별 건중량, T/R ratio), 묘목품질지수 (LWR, SWR, $\mathrm{RWR}, \mathrm{SQI}$ ), 엽록소 함량, 작업공정 (식재지 조성인력, 제초작 업 소요인력), 잡초발생량을 조사하였다.

형태적 생장특성과 부위별 물질 생산량은 부직포 멀칭 소재
$60 \mathrm{~g} / \mathrm{m}^{2}$ 겹치기 방식이 가장 우수하였으며. 묘목품질지수는 멀 칭 방식간의(겹치기 방식, 구멍뚫기 방식) 차이는 없지만, 멀칭 소재간의 $\left(60 \mathrm{~g} / \mathrm{m}^{2}, 80 \mathrm{~g} / \mathrm{m}^{2}\right)$ 차이는 있었다. 잡초 발생량에 따 른 작업공정의 총 소요인력은 부직포 멀칭 소재 $80 \mathrm{~g} / \mathrm{m}^{2}$ 겹치 기 방식이 가장 효율적인 것으로 조사되었다.

최종적으로 종가시나무 (Quercus glauca Thunb.) 1-2묘의 생산에 있어 잡초발생 억제 효과와 토양 내 습도가 유지되어 묘목의 생장 증진효과를 기대하는 처리구는 $60 \mathrm{~g} / \mathrm{m}^{2}$ 겹치기 방 식이 가장 적합하며, 식재지 조성인력과 제초작업 소요인력이 적어 경제적 비용이 절감될 것으로 기대되는 처리구는 $80 \mathrm{~g} / \mathrm{m}^{2}$ 겹치기 방식이 가장 적합한 것으로 나타났다.

따라서, 묘목 생산단계에 있어서는 $60 \mathrm{~g} / \mathrm{m}^{2}$ 겹치기 방식을 이 용하면 잡초발생 억제 및 생장 증진효과를 볼 수 있고, 묘목 이후 의 단계에 있어 제초작업에 소요되는 시간과 비용을 절감하기 위 해 $80 \mathrm{~g} / \mathrm{m}^{2}$ 겹치기 방식을 이용하면 도움이 될 것으로 판단된다. 멀칭은 넓은 면적에 조성해야 하는 수목 식재지 특성 상 경 제적인 부담을 줄일 수 있는 대안이 될 것이며, 추후 다양한 멀 칭 소재를 이용하여 멀칭처리가 묘목의 생육에 미치는 영향 구 명과 제초효과 검정 그리고 더 나아가 해당 묘목을 이식하였을 때 활착률에 관한 연구가 필요하다.

\section{References}

1. Arnon, D. I.(1949) Copper enzymes in isolated chloroplasts, polyphenoloxidase in Betula vulgaris. Pant Physiology 24: 1-15.

2. Baczek, K. R. and J. Koscielniak(2003) Antioxidative effect of elevated $\mathrm{CO}_{2}$ concentration in the air on maize hybrids subjected to serve chill. Photosynthetica 41(2): 161-165.

3. Bayala, J., M. Dianda, J. Wilson, S. J. Quedraogo and K. Sanon(2009) Predicting field performance of five irrigated tree species using seedling quality assessment in Burkina Faso, West Africa. New Forests 38(3): 309-322.

4. Blair, R. and F. Cech(1974) Morphological seedling grades cmpared after thirteen growing seasons. Tree Planters' Notes 25: 5-7.

5. Burdett, A. N.(1990) Physiological processes in plantation establishment and the development of specifications for forest planting stock. Canadian Journal of Forest Research 20: 415-427.

6. Carlson, W. C.(1986) Root system considerations in the quality of loblolly pine seedlings. Southern Journal of Applied Forestry 10: 87-92.

7. Choi, S. M., H. C. Shin, K. Y. Huh and H. J. Jeong(2012) Effects of underground container types on plant growth of Viburnum odoratissimum var. awabuki and Quercus glauca. J. Kor. Env. Red. Tech 15(3): 67-74.

8. Curtis, R. O.(1955) Use of graded nursery stock for red pine plantations. Joumal of Forestry 53: 71-173.

9. Davis, A. S. and D. F. Jacobs(2005) Quantifying root system quality of nursery seedlings and relationship to outplanting performance. New Forests 30: 295-311.

10. Deans, J. D., W. L. Mason, M. G. R. Cannell, A. L. Sharpe and L. J. Sheppard(1989) Growing regimes for bare-root stock of sitka spruce, douglas fir and scots pine. Morphology at the end of the nursery phase. Forestry 62: 53-60. 
11. Dickson, A., A. L. Leaf and J. F. Hosner(1960) Quality appraisal of white spruce and white pine seedling stock in nurseries. The Forestry Chronicle 36: 10-13

12. Haase, D.(2007a) Morphological and physiological evaluation of seedling quality. USDA Forest Service Proceedings RMRS-P-50.

13. Haase, D. (2007b) Understanding forest seedling quality: Measurements and interpretation. Tree Planter's Notes 52(1).

14. Hermann, R. K.(1964) Importance of top-root ratios for survival of Douglas-fir seedlings. Tree Planters' Notes 64: 7-11.

15. Hong, S. C., J. W. Heo, J. T. Lee and K. K. Kang(2011) Characteristics of reflective light over red and black plastic mulch, and effect on the quality and yield of the oriental melon and tomato. K. J. Environ Agric 30(4): 414-418,

16. Iyer, J. G. and S. A. Wilde(1982) A quick way to appraise the performance potential of tree planting stock. Tree Planters' Notes 33: 26-27.

17. Jensen, M. H.(1988) The achievements on the use of plastic in agriculture. International seminar on the utilization of the plastics in agriculture. Food \& Fertilizer Technology Center for the Asian and Pacific Region \& Rural Development Administration of Korea. pp. 1-17.

18. Jin, E. J., J. H. Yoon, E. J. Bae, S. M. Choi, Y. B. Park and M. S. Choi(2015) Effect of above and below-ground container cultivation on growth of Quercus glauca 4 years old seedlings. J. Agri \& Life Sci 49(6):9-17.

19. Johnson, F., J. Paterson, G. Leeder, C. Mansfield, F. Pinto and S. Watson(1996) Artificial regeneration of Ontario's Forest: Species and stock selection manual. Forest Research Information Paper No. 131.

20. Kang, A. R. and S. G. Park(2017) Growth and ground coverage of Ophiopogon japonicus 'Nanus' under different shade conditions. J. KILA 45(2): 68-75.

21. Kang, J. S., J. M. Suh, H. M. Shin, J. H. Cho and C. O. Hong(2013) Effects of compost application and plastic mulching on soil carbon sequestration in upland soil. K. J Environ Agric 32(4): 260-267.

22. Kim, J. H and S. J. Park(2010) An analysis of the yarfing productivity and cost in forest tending operation. J. K. For. Soc 99(4): 625-632.

23. Kim, J. H., D. H. Kim and D. H. Lee(2015) Effects of fertilizer treatment on the growth characteristics of 2-years old Pinus koraiensis Siebold \& Zucc container seedlings. J. Agri \& Life Sci 49(1): 63-70.

24. Lee, C. Y., T. J, Kim and G. J. Lee(2010) Effects of organic mulching on potato production and weed management. K. J. Org. Agri 18(4); 587-598.

25. Lee, K. W. and D. G. Kim(2017) Freezing injury of evergreen broad-leaved trees in warm-temperature in the southern region in Korea. J. K. Env. Res. Tech 20(1): 77-96.

26. Leiva, M. J. and R. Femandez-Ales(1998) Variability in seedling water status during drought within a Quercus ilex subsp. ballota population, and its relation to seedling morphology. Forest Ecology and Management 111: 147-156.

27. Lim, K. H., S. G. Kim, D. I. Seo, Y. W. Yang, Y. S. Kim, H. J. Kim and J. K. Kim(2009) The effects of mulching materials and weed control methods on growth and weed occurrence of pesticide-free
kale(Brassica oleracea L. var. acephala), K. J. Org. Agri 17(4): 501-517.

28. Mackinney, G.(1941) Absorption of light by chlorophyll solutions. Journal of Biological Chemistry 140: 315-322.

29. Mattsson, A.(1996) Prediction field performance using seedling quality assessment. New Forests 13.

30. Mullin, R. E. and C. Christl(1982) Morphological grading of white pine nursery stock. The Forestry Chronicle 58: 40-43.

31. Naidu, S. L. and E. H. Delucia(1998) Physiological and morphological acclimation of shade-grown tree seedlings to late-season canopy gap formation. Plant Ecology 138: 27-40.

32. National Institute of Biological Resources(https://species.nibr.go.kr)

33. Oh, G. K. and D. G. Kim(2006) Ecological Revengetation Engineering. Gwangil Publishing Co., Ltd.

34. Park, J. M., J. H. Kang, E. H. Jeong and G. W. Song(2004) Growth an yield of Atractylodes japonica Koidz. Affected by mulching methods. K. J. Medi Crop Sci 12(3) : 226-230.

35. Reynolds, J. F. and C. D'Antonio(1996) The ecological significance of plasticity in root weight ratio in response to nitogen: Opinion. Plant and Soil 185(1): 75-97.

36. Ritchie, G. A.(1984) Assessing seedling quality. In: Duryea, M. L. and T. D. Landis(Eds), Forest Nursery Manual 1: Production of Bareroot Seedlings. Martinus Nijh off Publishers. Netherlands. pp. 243-259.

37. Roh, S. W., Y. C. Ku, D. Y. Song, J. H. Park and K. Y. Seong(2004) Weed population distribution and change od dominant weed species on upland fields in Chungcheong region. K. J. Weed Sci 24(1):72-77.

38. Sagong, D. H., S. J. Lee, S. G. Han and T. M. Yoon(2011) The influence of materials for surface mulching on soil temperature and vegetative growth of apple nursery trees. K. J. Agri and Forest Mete 13(1): $1-9$

39. Šestak, Z., J. Èatský and P. G. Jarvis(1971) Plant photosynthetic production manual of methods. The Hague 818.

40. Shin, S. O., H. S. Shim, W. Y. Han, H. T. Kim, C. S. Jeong and I. Y. Baek(2012) Difference of growth chatacteristics and yield under P. E. filim mulching soybean cultivation in southern region og Korea. K. J. Intl. Agri 24(1): 12-21.

41. Sung, H. I., G. S. Song, Y. G. Cha and J. J. Kim(2011) Characteristics of growth and seedling quality of 1-year old Quercus myrsinaefolia by shading and fertilizing treatment. Journal of Korean Forest Society 100(4): 598-608.

42. Switzer G. L. and L. E. Nelson(1963) Effect of nursery fertility and density on seedling characteristics yield, and field perfomance of lobby pine(Pinus taeda L.). Soil Sci. Soc. Amer. Proc 27:461-464.

43. Thompson, B. E.(1985) Seedling morphological evaluation - What you can tell by looking. In : Proceedings, Evaluation Seedling Quality: Principles, Procedures, and Predictive Abilities of Major Tests. Durvea, M. L. (ed.), Forest Research Lab. Oregon State Univ, Corvallis.

44. Unger, P. W.(1978) Straw mulch effects on soil temperatures and sorghum germination and growth. Agron. J. 70: 858-864.

45. Yoon, J. H., K. S. jeon, K. S. Song, Y. B. Park, Y. S. Moon and D. H. Lee(2014) The growth and physiological responses of Cacalia firma seedlings by shading conditions in forest farming. J. K. For. Soc 130(1): $65-71$

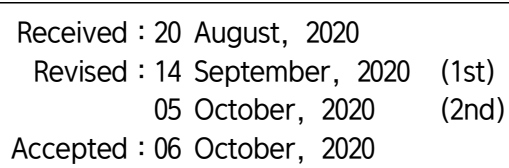

(2nd) 3인익명 심사필 